\title{
Glycaemic index of Indian flatbreads (rotis) prepared using whole wheat flour and 'atta mix'-added whole wheat flour
}

\author{
Ganesan Radhika ${ }^{1}$, Chandhrasekar Sumathi ${ }^{1}$, Anbazhagan Ganesan ${ }^{1}$, Vasudevan Sudha ${ }^{1}$, \\ Christiani Jeya Kumar Henry ${ }^{2}$ and Viswanathan Mohan ${ }^{1} *$ \\ ${ }^{1}$ Madras Diabetes Research Foundation, Dr Mohan's Diabetes Specialities Centre, WHO Collaborating Centre for \\ Non-Communicable Diseases, International Diabetes Federation (IDF) Centre of Education, 4, Conran Smith Road, Gopalapuram, \\ Chennai, India \\ ${ }^{2}$ Nutrition and Food Science Group, School of Life Sciences, Oxford Brookes University, Gipsy Lane Campus, Headington, Oxford \\ $O X 3 O B P, U K$
}

(Received 19 March 2009 - Revised 11 November 2009 - Accepted 27 November 2009 - First published online 26 January 2010)

\begin{abstract}
To compare the glycaemic index (GI) of newly developed 'atta mix' roti with whole wheat flour roti. Eighteen healthy non-diabetic subjects consumed $50 \mathrm{~g}$ available carbohydrate portions of a reference food (glucose) and two test foods (whole wheat flour roti and atta mix roti) in random order after an overnight fast. The reference food was tested on three separate occasions, while the test foods were each tested once. Capillary blood samples were measured from finger-prick samples in fasted subjects ( -5 and 0 min) and at $15,30,45,60,90$ and 120 min from the start of each food. No significant difference was observed between roti prepared from whole wheat flour and atta mix in terms of appearance, texture, flavour, taste or acceptability. For each test food, the incremental area under the curve and GI values were determined. The GI of atta mix roti (27.3 (SEM 2.2)) was considerably lower than the whole wheat flour roti (45.1 (SEM 3.5), P<0.001). Development of foods with lower dietary glycaemic load such as the atta mix roti could help in the prevention and control of diabetes in South Asian populations, which habitually consume very high glycaemic load diets.
\end{abstract}

Glycaemic index: Roti: Atta mix: Diet: Nutrition: Epidemiology: Diabetes: Asian Indians: South Asians

A number of studies over the past 20 years have shown the beneficial effects of low glycaemic index (GI) foods in relation to development of chronic diseases such as type 2 diabetes (T2D) ${ }^{(1)}$ and $\mathrm{CVD}^{(2)}$. The United Nations FAO/ WHO (1998) report recommends that the GI of foods be used in combination with information about food composition to guide food choices for better management and prevention of chronic diseases such as T2D and $\mathrm{CVD}^{(3)}$.

India already has the highest number of people with T2D in the world $^{(4)}$. Controlling postprandial blood sugar is important for the prevention and control of T2D and its related complications $^{(5,6)}$. There is a large body of evidence to suggest that if a reduction in postprandial glycaemia is to be part of the strategy for prevention and management of diabetes and CVD, the GI (or quality) is as relevant as the quantity of carbohydrate $^{(1,7)}$. Foods low in GI may reduce the insulin demand ${ }^{(8)}$, improve blood glucose control ${ }^{(8)}$, reduce blood lipid concentrations $^{(9)}$ and body weight ${ }^{(10-12)}$ and thereby could help prevent diabetes-related cardiovascular events ${ }^{(13-15)}$.

Carbohydrate foods (cereal-based), particularly rice and wheat $(60-65 \%)$, provide the bulk of the energies in the Asian Indian diet ${ }^{(16)}$. Rice consumption is higher in southern ${ }^{(17)}$ and eastern parts of the country, while wheat consumption is higher in northern India ${ }^{(18)}$. Almost half $(46.9 \%)$ of the daily energies among South Indian population is derived from refined grains (mean intake $333 \mathrm{~g} / \mathrm{d}$ ) of which white rice is a major contributor (mean intake $253.4 \mathrm{~g} / \mathrm{d}$ ) ${ }^{(17)}$. Understanding the GI of such staples is necessary for the proper selection of foods and may be of particular benefit to Indians, who are more insulin resistant ${ }^{(19,20)}$. It is only quite recently that whole grain-based foods of traditional Indian diets have been reintroduced in the Indian market, but the GI of most products has not been tested. There is hence a need to determine the GI of local food products using standardised methodology $y^{(3,21)}$. In the present study, we compare the GI of rotis (unleavened flatbread) made of whole wheat flour and with a newly developed atta mix containing bengal gram, psyllium husk and debittered fenugreek flour in healthy non-diabetic subjects.

\section{Materials and methods}

\section{Subjects}

Non-diabetic healthy volunteers aged between 18 and 45 years were recruited from the diabetes centre, which included

\footnotetext{
Abbreviations: GI, glycaemic index; GL, glycaemic load; IAUC, incremental area under the curve; T2D, type 2 diabetes.

*Corresponding author: Dr Viswanathan Mohan, fax +91 442835 0935, email drmohans@vsnl.net
} 
staff/students or their relatives. Subjects were excluded if BMI was $>22.9 \mathrm{~kg} / \mathrm{m}^{2}$. According to the WHO Asian Pacific guidelines, overweight in Asians is defined as BMI $>22.9 \mathrm{~kg} / \mathrm{m}^{2}$ and obesity as $\geq 25 \mathrm{~kg} / \mathrm{m}^{2(22)}$. Subject characteristics do not appear to have a significant effect on mean GI values, and therefore for routine testing, healthy human volunteers are recommended ${ }^{(23)}$. Subjects were also excluded if fasting blood glucose value $>5.6 \mathrm{mmol} / \mathrm{l}^{(24)}$, if they were on any special diet, had a family history of diabetes, were suffering form any illness or food allergies or were on any medication. A total of thirty subjects volunteered to participate in the GI testing, of whom five were dropped, one due to change in BMI and four due to sickness. Three subjects were excluded because they had impaired glucose tolerance and an additional four subjects were excluded as they were found to be outliers (individual GI values greater or lesser than 2 SD of the mean GI values). Thus, a total of eighteen subjects (twelve men and six women) were included in the analysis.

Anthropometric measurements including height, weight and waist circumference were taken in the fasting state using standardised techniques as described elsewhere ${ }^{(21)}$. The present study was conducted according to the guidelines laid down in the Declaration of Helsinki, and all procedures involving human subjects were also approved by the institution's Ethical Committee of the Madras Diabetes Research Foundation. Subjects were given full details of the study protocol and the opportunity to ask questions. All subjects gave written informed consent before participation.

\section{Experimental protocol}

The protocol used to measure GI was adapted from that described by Wolever et al. ${ }^{(25)}$ and Brouns et al. ${ }^{(23)}$ and is in line with procedure recommended by the $\mathrm{FAO} / \mathrm{WHO}^{(3)}$. The procedure has been standardised with an international laboratory that took part in an Inter-laboratory study ${ }^{(26)}$ and has been published elsewhere ${ }^{(21)}$. In the present study, the number of subjects has been increased to detect the small differences in GI and to ensure greater precision ${ }^{(23)}$.

On the day before the test, subjects were asked not to smoke, consume alcohol, to undertake any vigorous physical activity and to consume their usual meal of similar size and composition, which was verified by a $24 \mathrm{~h}$ dietary recall and a brief questionnaire on behavioural status. If there was any deviation, the appointments were rescheduled. Subjects visited the GI testing centre in the morning after a $10-12 \mathrm{~h}$ overnight fast, which was standardised to within $\pm 15 \mathrm{~min}$ of the chosen interval on all five occasions.

\section{Test food}

The portion size of the test foods (whole wheat flour and atta mix) was calculated using the available carbohydrate estimated as per Association of Official Analytical Chemists (AOAC) method ${ }^{(27)}$. Available carbohydrate content of the wheat flour was determined after gelatinising the flour using direct measurement, although there is a possibility that some available carbohydrate may be lost during the cooking process. Branded commercial whole wheat flour (Pillsbury, General Mills India Pvt. Ltd., Mumbai, India) was purchased from the super market, and was used to prepare the whole wheat flour roti. Atta mix is a proprietary (patented), functional food, made of roasted bengal gram flour (legumes), psyllium/ispaghula husk powder (the husk of the seeds of Plantago ovata) and debittered fenugreek (methi) powder. This mix was used in the ratio (4.4:1) of $459 \mathrm{~g}$ atta mix added to $2 \mathrm{~kg}$ whole wheat flour, as recommend by the manufacturer (Marico Ltd. K.C. Marg, Mumbai, India), and the cooking procedure was standardised by a nutritionist. Roti was prepared from dough that was rolled out to approximately $15 \mathrm{~cm}$ in diameter, cooked fairly well on both sides on hot griddle and tossed on direct flame to puff. Description and macronutrient composition and fibre content of the test foods are shown in Tables 1 and 2. Sensory attributes of roti were rated using a $15 \mathrm{~cm}$ structured graphical hedonic scale ${ }^{(28)}$.

\section{Reference food}

Fifty-five grams of dextrose (glucose monohydrate) dissolved in $200 \mathrm{ml}$ water were used as the reference food (Glucon-D ${ }^{\circledR}$ glucose powder, Heinz India (P) Ltd., Mumbai, India). The reference food was consumed during the first, middle and last test sessions, while the two types of roti were consumed in random order in between the reference food sessions ${ }^{(23)}$, with at least $3 \mathrm{~d}$ gap between measurements to minimise carry-over effects. Subjects were given $200 \mathrm{ml}$ water along with the test food and an extra $200 \mathrm{ml}$ was given during the subsequent $2 \mathrm{~h}$.

\section{Blood glucose measurement}

Fasting blood samples were obtained by collecting finger-prick capillary blood samples, at $-5 \mathrm{~min}$ and $0 \mathrm{~min}$. The baseline value was taken as the mean of these two values. The subjects then consumed the reference/test food immediately after this. The first bite in the mouth is set as time 0 and the first

Table 1. Description of the test foods

\begin{tabular}{lcc}
\hline Test foods & Whole wheat flour roti & Atta mix roti \\
\hline Available carbohydrate content $(\mathrm{g} / 100 \mathrm{~g})^{\star}$ & 75 & 67 \\
Raw sample weight providing $50 \mathrm{~g}$ available carbohydrate $(\mathrm{g})$ & 67 & 75 \\
Cooking method and equipment used & Dry heat method using non-stick pan and puffing on flame \\
Amount of water $(\mathrm{ml})$ & 50 & 56 \\
Dough weight $(\mathrm{g})$ & 115 & 127 \\
Per chappathi average cooked weight $(\mathrm{g})$ & $30 \cdot 2 \mathrm{~g}$ & $30 \cdot 5 \mathrm{~g}$ \\
& $(15 \mathrm{~cm}$ in diameter $)$ & $(15 \mathrm{~cm}$ in diameter) \\
\hline
\end{tabular}

Available carbohydrate value on dry weight basis.

* Glycemic Index Testing Laboratory, Madras Diabetes Research Foundation, India. 
Table 2. Macronutrient and dietary fibre content of the test foods*

\begin{tabular}{lcr}
\hline Nutritional information & $\begin{array}{c}\text { Whole wheat flour } \\
\text { (commercial; } 100 \mathrm{~g})\end{array}$ & $\begin{array}{c}\text { Atta mix } \\
(100 \mathrm{~g})\end{array}$ \\
\hline Energy $(\mathrm{kJ})$ & 1012.5 & 1142.2 \\
Total fat $(\mathrm{g})$ & 1.3 & 1.7 \\
Protein $(\mathrm{g})$ & 8.4 & 9.8 \\
Available carbohydrate $(\mathrm{g}) \S$ & 50.2 & 50.3 \\
Total dietary fibre $(\mathrm{g})$ & 7.1 & 10.9 \\
\hline
\end{tabular}

*Test foods are whole wheat flow (commercial), atta mix.

†Source: from the Food and Nutrition label: ingredient: whole wheat atta, no additives or preservatives used.

¥ Source: from Food and Nutrition label: ingredient: roasted bengal gram flour, psyllium husk powder and debittered fenugreek powder. Whole wheat atta (commercial) and atta mix was mixed in the ratio of $4 \cdot 4: 1$.

$\S$ Available carbohydrate by direct method.

blood sample is taken exactly $15 \mathrm{~min}$ afterwards. Further blood samples were obtained at 30, 45, 60, 90 and $120 \mathrm{~min}$ after the start of the test meal. Capillary blood sample was used in order to improve sensitivity and to remove the potential for variations in measured GI due to fluctuations in factors such as ambient temperature ${ }^{(3,26,29)}$. Blood glucose was measured using an automatic lancet device (Accu-Chek ${ }^{\circledR}$ Sensor, Roche Diagnostics GmbH, Mannheim, Germany), which was calibrated daily using the control solution and the Hemocue Glucose $201+$ analyzer (Hemocue ${ }^{\circledR}$ Ltd, Angelholm, Sweden). The reliability of the glucometer was tested against Hemocue ${ }^{\circledR}$ analyzer among twenty-four volunteers by measuring the incremental area under the curve (IAUC). The CV was $2.5 \%$ and the correlation coefficient of IAUC values was $r 0.989, P<0.001$.

\section{Calculation of the glycaemic index}

The incremental area under the blood glucose response curves (IAUC) to test and reference foods were calculated geometrically using the trapezoid rule $(\mathrm{FAO} / \mathrm{WHO})^{(3)}$, ignoring the area beneath the baseline. For each subject, a GI value for each test food was calculated by expressing each subject's IAUC after the test food as a percentage of the same subject's mean reference IAUC.

\section{GI value for test food $(\%)=(($ Blood glucose IAUC value for the test food)/(Mean IAUC value for the same available carbohydrate portion of the reference food) $) \times 100$.}

Individual GI values for any subject that were greater or less than $2 \mathrm{SD}$ of the group mean GI were considered to be outliers and were excluded from the analysis.

\section{Statistical analysis}

Statistical analyses were performed with SAS software (version 9.1; SAS institute, Cary, NC, USA). Data are shown as means with their standard errors unless otherwise stated. Before statistical analysis, the normality of the data was tested using the Shapiro-Wilks statistics. The significance of difference between test foods was tested by paired $t$ test. Levels of inter- and intra-individual variation of the three reference (glucose) tests were assessed by determining
$\mathrm{CV} \%$. Using analysis of covariance, the effects of age, sex and BMI on GI were analysed for the two test foods. Statistical significance was set at $P<0 \cdot 05$.

\section{Results}

The demographic and clinical characteristics of the study subjects are presented in Table 3 . The results of the sensory evaluation of the atta mix roti showed no significant difference in terms of appearance (10 (SEM 0.4) v. 11 (SEM 0.6)), texture (10 (SEM 0.5) v. 11 (SEM 0.6)), flavour (11 (SEM 0.4) v. 10 (SEM 0.4)), taste (10 (SEM 0.5) v. 11 (SEM 0.6)) and overall acceptability (11 (SEM 0.4) v. 10 (SEM 0.5)) in comparison with whole wheat flour roti.

The mean fasting blood glucose was similar before each test meal, 4.95 (SEM 0.08) $\mathrm{mmol} / \mathrm{l}$ for whole wheat flour roti, 5.05 (SEM 0.07) $\mathrm{mmol} / \mathrm{l}$ for atta mix roti and 4.97 (SEM 0.06) $\mathrm{mmol} / \mathrm{l}$ $(P=0.605)$ for the glucose. The blood glucose response to atta mix roti was significantly lower at $30(P=0.025), 45$ $(P=0.005), 60(P=0.009)$ and $90 \mathrm{~min}(P=0.016)$ compared to the whole wheat flour roti, and the mean blood glucose response curve of the two test foods are shown in Fig. 1.

Table 4 shows the mean IAUC and GI of the test foods. The mean IAUC of atta mix roti $(66.2$ (SEM 6.94) mmol/l) was significantly lower than the whole wheat flour roti (109.6 (SEM 10.6) mmol/l, $P<0.001$ ). The mean GI of atta mix roti showed significantly lower $(27 \cdot 3$ (SEM 2.2)) value than the whole wheat flour roti (45.1 (SEM 3.5), $P<0.001)$, which represents a $39.5 \%$ decreases in GI value. The mean intraindividual CV glucose tested thrice was $23 \cdot 2$ (SEM 2.4) \%. The individual values for reference $\mathrm{CV}$ were negatively related to the mean IAUC values $\left(r^{2} 0.247, P=0.036\right)$, but were not related to sex, age, BMI or effect of test foods.

\section{Discussion}

The study reports on GI of Indian rotis prepared using whole wheat flour and with atta mix. The present study results demonstrate that both the whole wheat flour and atta mix rotis show lower GI. However, the atta mix rotis had $39.5 \%$ lower GI units as compared to whole wheat flour roti. This would be of great relevance in the context of southeast Asia, which is currently the epicentre of the diabetes epidemic $^{(4,30,31)}$ and where the diets that usually consist of high carbohydrate-based foods (cereal staples) leading to high glycaemic load $(\mathrm{GL})^{(17)}$. We have recently shown that $\mathrm{GL}$ is an independent risk factor for $\mathrm{T}_{2} \mathrm{D}^{(32)}$ and low HDL

Table 3. Demographic and clinical characteristics of the subjects studied ( $n$ 18)

(Mean values with their standard errors and ranges)

\begin{tabular}{|c|c|c|c|}
\hline Variables & Mean & SEM & Range \\
\hline Males/females $(n)$ & $12 / 6$ & - & - \\
\hline Age (years) & $23 \cdot 6$ & 0.6 & $18-31$ \\
\hline Weight (kg) & $56 \cdot 1$ & 1.6 & $46 \cdot 2-68 \cdot 0$ \\
\hline Height (cm) & $164 \cdot 3$ & $2 \cdot 1$ & $148 \cdot 0-179 \cdot 8$ \\
\hline BMI $\left(\mathrm{kg} / \mathrm{m}^{2}\right)$ & $20 \cdot 7$ & 0.2 & $19 \cdot 3-22 \cdot 2$ \\
\hline Waist circumference (cm) & $72 \cdot 3$ & 1.5 & $64 \cdot 1-81 \cdot 3$ \\
\hline Fasting blood sugar (mmol/l) & $5 \cdot 1$ & 0.1 & $4.4-6.5$ \\
\hline
\end{tabular}




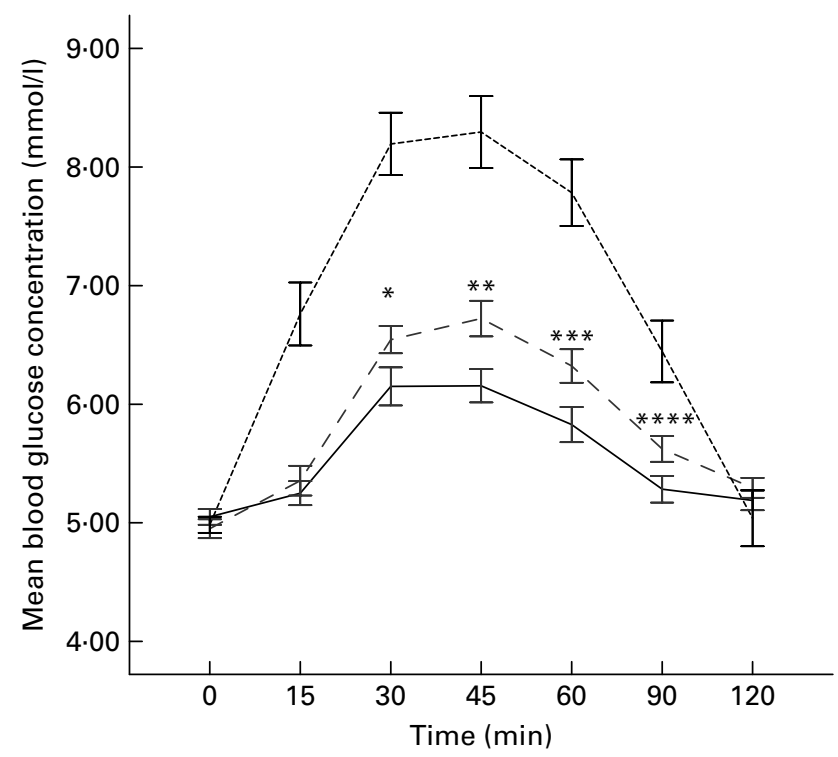

Fig. 1. Graphical representation showing mean blood glucose concentrations between reference (glucose), whole wheat flour roti and atta mix roti ( $n$ 18). Mean values were significantly different between atta mix roti and whole wheat flour roti: * $P=0.025 ;{ }^{\star \star} P=0.005 ;{ }^{\star \star \star} P=0.009 ;{ }^{\star \star \star \star} P=0.016$. --, Glucose; - -, whole wheat flour roti; - , atta mix roti.

concentration, a component of metabolic syndrome ${ }^{(33)}$. Use of atta mix rotis could help to reduce the dietary GL of the diet consumed in this part of the world.

The present results cannot be directly compared with the previously published values ${ }^{(34,35)}$ as studies on wheat chappathi were done on mixed meals rather than on a single food. However, a study conducted by Chaturvedi et al. ${ }^{(34)}$ showed medium GI $(66 \%)$ for a chappathi served with bottle gourd and tomato curry. A study by Urooj \& Puttaraj ${ }^{(35)}$ showed two extreme GI ranges (44-81\%) for chappathi, wheat flour, thin, with green gram dhal. These differences could be due to wheat with varied gluten content, the method of processing and preparation such as type of fat, dry roasting (amount of resistant starch formed during dry toasting) ${ }^{(36)}$, presence of antinutrients and addition of salt ${ }^{(37)}$, all which have been shown to influence the GI of roti. However, none of the earlier studies have evaluated different types of rotis, with respect to their GI.

The whole wheat flour roti tested in the present study also showed low GI, as it contains the whole grain components (wheat bran and germ) that are well known for its lower glycaemic response ${ }^{(38)}$. Studies have also found that the $\alpha$-amylase inhibitors present in wheat, which can withstand cooking temperature, are effective in reducing blood glucose response $^{(39)}$. All these factors perhaps lowered the GI of whole wheat flour chappathi.

The therapeutic effects of bengal gram (legume) ${ }^{(40)}$, psyllium/ispaghula husk ${ }^{(41,42)}$ and debittered fenugreek powder ${ }^{(43-45)}$ on lowering postprandial glucose levels are probably due to high viscous soluble fibre, the galactomannans (polysaccharides) that are not hydrolysed by the digestive enzymes. In contrast to insoluble fibre, soluble fibre results in high viscous intestinal contents with gelling properties that could delay gastric emptying and also intestinal absorption $^{(46)}$. The soluble fibre content of the atta mix was not provided in the nutrition label and to measure the same is beyond the scope of the present study. However, published nutritive value of Indian foods ${ }^{(47)}$ showed appreciable amount of soluble fibre content in bengal gram dhal $(2.6 \mathrm{~g} / 100 \mathrm{~g}$ edible portion) and in fenugreek seeds $(20.0 \mathrm{~g} / 100 \mathrm{~g}$ edible portion). When galactomannans from bengal gram, psyllium and fenugreek seeds are well mixed with the carbohydrate portion of the food, it may change the physical availability of carbohydrate to hydrolytic enzymes thus converting the carbohydrates to a slow release form, thereby lowering the plasma glucose levels ${ }^{(40,48,49)}$. In the present study, we note that the addition of atta mix to wheat flour neither changed the sensory characteristics nor the intrinsic food matrix of the whole wheat flour and yet showed significant drop in the GI units by $39.5 \%$. The outliers were removed for the calculations of IAUC and this could have 'artificially' lowered the coefficients of variation for AUC and GI values. However, this did not misclassify the GI values.

In the present study, age, sex, BMI or individual GI values were not related to intra-subject variation as measured by the $\mathrm{CV}$ of the reference food. This is consistent with a previously published study from our centre ${ }^{(21)}$ and other reported values $^{(26,29)}$, which suggests that GI is a property of food and not of the subject in whom it is measured.

Our previously published works ${ }^{(32,33)}$ and studies from the West $^{(13,14)}$ had shown that the diets with a high glycaemic load and decreased intake of whole grains and fibre were positively associated with the risk of T2D. In the present study, GL of whole wheat flour roti (22.6/test feed serving) was higher than the atta mix roti (GL: $13 \cdot 7 /$ test feed serving). Thus, this could potentially benefit South Asians, as rotis consumed as the staple food, especially in the northern states of India. However, prospective studies using low GL diets are needed to see whether diabetes can be prevented using this approach.

The present study is the first of its kind to test the GI of whole wheat flour and atta mix using validated standardised GI protocol ${ }^{(21)}$. Our subjects also showed low intra-individual

Table 4. Incremental area under the curve (IAUC) and glycaemic index (GI) of the test foods ( $n$ 18) (Mean values with their standard errors)

\begin{tabular}{lcccccc}
\hline & \multicolumn{2}{c}{ IAUC } & & \multicolumn{2}{c}{ GI } & \\
\cline { 2 - 3 } Test foods & Mean & SEM & & Mean & SEM & GI classification \\
\hline Whole wheat flour roti & 109.6 & $10 \cdot 6$ & & $45 \cdot 1$ & 3.5 & Low \\
Atta mix roti & $66 \cdot 2^{*}$ & 6.9 & & $27 \cdot 3^{*}$ & 2.2 & Low \\
\hline
\end{tabular}

${ }^{*} P$ value $(<0.001)$ refers to differences in IAUC and GI values between atta mix roti and whole wheat flour roti. 
(within-subject) variability for repeated tests of the reference food $(23 \%)$, which is substantially lower than that recorded by others ${ }^{(50)}$. Future studies should consider the measurement of insulin in addition to glycaemic response, as some low GI foods produce excessive insulin levels.

In conclusion, both whole wheat roti and atta mix roti show low GI food values. Hence, both could be incorporated into the Indian diets to replace existing high GI food choices such as refined grains. However, selecting the atta mix could further reduce the overall dietary glycaemic load which could be beneficial in a population, which is highly susceptible to $\mathrm{T} 2 \mathrm{D}$ and insulin resistance ${ }^{(51)}$.

\section{Acknowledgements}

We thank the volunteers participated in the GI testing study. Our special thanks to Ms P. Muthumariyammal and Ms Tamil Selvi for assisting in the manuscript. This is the first publication from our GI testing centre. The present study was supported by the Marico Limited, Mumbai, India, and we wish to thank Mr Anand and Mrs Ankita for their support.

V. M. is the guarantor. V. M., V. S. and G. R. planned and designed the study. G. R. and C. S. conducted the study. G. R. and A. G. contributed to the data analysis. G. R. wrote the first draft of the manuscript. V. M. and V. S. rewrote the subsequent drafts. V. M., V. S., G. R. and C. J. K. H. contributed the interpretation of the data and all contributors participated in the revision and final draft of the manuscript. They approved the final version and will take public responsibility for the content of the present paper. There are no conflicts of interest any with other organisation.

\section{References}

1. Jenkins DJ, Kendall CW, McKeown-Eyssen G, et al. (2008) Effect of a low-glycemic index or a high-cereal fiber diet on type 2 diabetes: a randomized trial. JAMA 300, 2742-2753.

2. Barclay AW, Petocz P, McMillan-Price J, et al. (2008) Glycemic index, glycemic load, and chronic disease risk - a meta-analysis of observational studies. Am J Clin Nutr 87, 627-637.

3. FAO/WHO (1998) Carbohydrates in human nutrition: Report of joint FAO/WHO expert consultation. FAO Food Nutr Pap 66, $1-140$.

4. Unwin N, Whiting D, Gan D, et al. (editors) (2009) In Diabetes Atlas, 4th ed. Belgium: International Diabetes Federation pp. 12.

5. Alberti KG, Zimmet P \& Shaw J (2007) International Diabetes Federation: a consensus on type 2 diabetes prevention. Diabet Med 24, 451-463.

6. UK Prospective Diabetes Study (UKPDS), Group (1998) Intensive blood-glucose control with sulfonylureas or insulin compared with conventional treatment and risk of complications in patients with type-2 diabetes (UKPDS 33). Lancet 352, $837-853$

7. Brand-Miller J, Hayne S, Petocz P, et al. (2003) Low-glycemic index diets in the management of diabetes: a meta-analysis of randomized controlled trials. Diabetes Care 26, 2261-2267.

8. Rizkalla SW, Taghrid L, Laromiguiere M, et al. (2004) Improved plasma glucose control, whole-body glucose utilization, and lipid profile on a low glycemic index diet in type diabetic men: a randomized trial. Diabetes Care 27, 1866-1872.

9. Kelly S, Frost G, Whittaker V, et al. (2004) Low glyacemic index diets for coronary heart disease. Cochrane Database of Systematic Reviews 2004, issue 4 CD004467.
10. Ebbeling CB, Leidig MM, Sinclair KB, et al. (2003) A reducedglycemic load diet in the treatment of adolescent obesity. Arch Pediatr Adolesc Med 157, 773-779.

11. McMillan-Price J, Petocz P, Atkinson F, et al. (2006) Comparison of 4 diets of varying glycemic load on weight loss and cardiovascular risk reduction in overweight and obese young adults. Arch Intern Med 166, 1466-1475.

12. Slabber M, Barnard HC \& Kuyl JM (1994) Effects of low-insulin-response, energy-restricted diet on weight loss and plasma insulin concentrations in hyperinsulinemic obese females. Am J Clin Nutr 60, 48-53.

13. Salmerón J, Ascherio A, Rimm EB, et al. (1997) Dietary fiber, glycemic load, and risk of NIDDM in men. Diabetes Care 20, $545-550$.

14. Salmeron J, Manson JE, Stampfer MJ, et al. (1997) Dietary fiber, glycemic load, and risk of non-insulin-dependent diabetes mellitus in women. JAMA 277, 472-477.

15. Liu S, Willett WC, Stampfer MJ, et al. (2000) A prospective study of dietary glycemic load, carbohydrate intake, and risk of coronary heart disease in US women. Am J Clin Nutr 71, 1455-1461.

16. The double burden of malnutrition (2006) Case studies from developing countries. FAO Food and Nutrition Paper 84, Food and Agricultural Organization of the United Nations Rome, 84, 99-160.

17. Radhika G, VanDam R, Sudha V, et al. (2009) Refined grain consumption and the metabolic syndrome in urban Asian Indians [CURES-57]. Metabolism 58, 675-681.

18. Chatterjee S, Rae A \& Ray R Food Consumption and calorie intake in contemporary India, April 2007. https://editorialexpress.com/ cgi-in/conference/download.cgi (accessed 10 January 2008).

19. Mohan V, Sharp PS \& Cloke HR (1986) Serum immunoreactive insulin responses to glucose load in Asian Indian and European type 2 (non-insulin-dependent) diabetic patients and control subjects. Diabetologia 29, 235-237.

20. Sharp PS, Mohan V, Levy JC, et al. (1986) Insulin resistance in patients of Asian Indian and European origin with noninsulin-dependent diabetes. Horm Metab Res 29, 235-237.

21. Henry CJ, Lightowler HJ, Newens K, et al. (2008) Glycaemic index of common foods tested in the UK and India. Br J Nutr 99, 840-845.

22. Regional Office for the Western Pacific of the World health Organization (2000) World Health Organization, International Association for the Study of Obesity and International Obesity Task Force. The Asia Pacific Perspective; Redefining Obesity and its Treatment. Sydney: Health Communications Australia Pty Lts, pp. 17-21.

23. Brouns F, Bjorck I, Frayn KN, et al. (2005) Glycemic index methodology. Nutr Res Rev 18, 145-171.

24. The American Diabetes Association (2007) Diagnosis and classification of diabetes mellitus. Diabetes Care 30, Suppl. 1, S42-S47.

25. Wolever TMS, Jenkins DJA, Jenkins AL, et al. (1991) The glycemic index: methodology and clinical implications. Am J Clin Nutr 54, 846-854.

26. Wolever TM, Brand-Miller JC, Abernethy J, et al. (2008) Measuring the glycemic index of foods: interlaboratory study. Am J Clin Nutr 87, Suppl. 1, 247S-257S.

27. Englyst HN \& Cummings JH (1990) Non-starch polysachharides (dietary fiber) and resistant starch. In New Developments in Dietary Fiber. Physiological, Physiochemical, and Analytical Aspects, pp. 205-225 [I Furda and CJ Brine, editors]. New York/London: Plenum Press.

28. Holt SHA, Brand Miller JC, Petocz P, et al. (1995) A satiety index of common foods. Eur J Clin Nutr 49, 675-690.

29. Wolever TM, Vorster HH, Bjorck I, et al. (2003) Determination of the glycaemic index of foods: interlaboratory study. Eur $J$ Clin Nutr 57, 475-482. 
30. Mohan V, Deepa M, Deepa R, et al. (2006) Secular trends in the prevalence of diabetes and impaired glucose tolerance in urban South India - the Chennai Urban Rural Epidemiological Study (CURES-17). Diabetologia 49, 1175-1178.

31. Ramachandran A, Mary S, Yamuna A, et al. (2008) High prevalence of diabetes and cardiovascular risk factors associated with urbanization in India. Diabetes Care 31, 893-898.

32. Mohan V, Radhika G, Sathya RM, et al. (2009) Dietary carbohydrates, glycaemic load, food groups and newly detected type 2 diabetes among urban Asian Indian population in Chennai, India (Chennai Urban Rural Epidemiology Study 59). Br J Nutr 102, 1498-1506.

33. Radhika G, Ganesan A, Sathya RM, et al. (2009) Dietary carbohydrates, glycemic load and serum high-density lipoprotein cholesterol concentrations among South Indian adults. Eur J Clin Nutr 63, 413-420.

34. Chaturvedi A, Sarojini G, Nirmala G, et al. (1997) Glycemic Index of grain amaranth, wheat and rice in NIDDM subjects. J Plant Foods Hum Nutr 50, 171-178.

35. Urooj A \& Puttaraj S (2000) Glycaemic responses to cerealbased Indian food preparations in patients with non-insulindependent diabetes mellitus and normal subjects. $\mathrm{Br} \mathrm{J} \mathrm{Nutr}$ 83, 483-488.

36. Thorne MJ, Thompson L \& Jenkins DJ (1983) Factors affecting starch digestibility and the glycaemic response with special reference to legumes. Am J Clin Nutr 38, 481-488.

37. Brand JC, Nicholson PL, Thorburn AW, et al. (1985) Food processing and glycemic index. Am J Clin Nutr 42, 1192-1196.

38. Holm J, Hadander B, Bjorck I, et al. (1989) The effect of various thermal processes on the glycemic response to whole grain wheat products. $J$ Nutr 119, 1631-1638.

39. Urooj A \& Puttaraj (1988) Glycemic index of foods - new concepts in carbohydrate bioavailability. Arogya J Health Sci 14, 7-23.

40. Dilawari JB, Kamath PS \& Batta RP (1981) Reduction of postprandial plasma glucose by Bengal gram dal (Cicer arietinum) and rajmah (Phaseolus vulgaris). Am J Clin Nutr 34, $2450-2453$
41. Ziai SA, Larijani B \& Akhoondzadeh S (2005) Psyllium decreased serum glucose and glycosylated hemoglobin significantly in diabetic outpatients. J Ethnopharmacol 102, 202-207.

42. Sierra M, García JJ, Fernández N, et al. (2002) Therapeutic effects of psyllium in type 2 diabetic patients. Eur J Clin Nutr 56, 830-842.

43. Madar Z, Abel R, Samish S, et al. (1988) Glucose lowering effect of fenugreek in non-insulin dependent diabetics. Eur $J$ Clin Nutr 42, 51-54.

44. Broca C, Gross R, Petit P, et al. (1999) 4-Hydroxyisoleucine: experimental evidence of its insulinotropic and antidiabetic properties. Am J Physiol 277, 617-623.

45. Sharma RD \& Raghuram TC (1990) Hypoglycemic effect of fenugreek seeds in non-insulin dependent diabetes mellitus. Nutr Res 10, 731-739.

46. Jenkins DJ, Jenkins MJ, Wolever TM, et al. (1986) Slow release carbohydrate: mechanism of action of viscous fibers. J Clin Nutr Gastroenterology 1, 237-241.

47. Gopalan C, Sastri BV \& Balasubramanian S (1985) Revised and updated by Narasinga Rao BS, Deosthale YG \& Pant KC (reprinted on 2007) Nutritive Value of Indian Foods. National Institute of Nutrition, Indian Council of Medical Research Hyderabad, pp. 93-95.

48. Hallfrish J \& Behall KM (2000) Mechanism of the effects of grains on insulin and glucose responses. J Am Coll Nutr 19, Suppl. 3, 320S-325S.

49. Brennan CS, Blake DE, Ellis PR, et al. (1996) Effects of guar galactomannan on wheat bread microstructure and on the in vitro and in vivo digestibility of starch in bread. $J$ Cereal Sci 24, 151-160.

50. Vega-Lopez S, Ausman L, Griffith J, et al. (2007) Interindividual variability and intra-individual reproducibility of glycemic index values for commercial white bread. Diabetes Care 30, 1412-1417.

51. Mohan V \& Deepa R (2006) Adipocytokines and the expanding 'Asian Indian phenotype'. J Assoc Physicians India 54, $685-686$ 